\title{
Three-dimensional printing in congenital heart disease
}

\author{
Joshua L. Hermsen, Alejandro Roldan-Alzate, Petros V. Anagnostopoulos \\ University of Wisconsin-Madison and American Family Children's Hospital, Madison, WI, USA \\ Contributions: (I) Conception and design: JL Hermsen; (II) Administrative support: None; (III) Provision of study materials or patients: All authors; \\ (IV) Collection and assembly of data: JL Hermsen; (V) Data analysis and interpretation: T Uchida; (VI) Manuscript writing: All authors; (VII) Final \\ approval of manuscript: All authors. \\ Correspondence to: Joshua L. Hermsen, MD. 600 Highland Avenue, Clinical Sciences Center, H4/352, Madison, WI 53792, USA. \\ Email: hermsen@surgery.wisc.edu.
}

\begin{abstract}
Three-dimensional printing (3Dp) has a broad array of medical applications and has been applied extensively in congenital heart disease given the variety and complexity of lesions encountered. 3Dps are unique when compared to other imaging modalities in that they are theoretically equally interpretable by radiologists, cardiologists and surgeons. The literature regarding $3 \mathrm{Dp}$ in congenital heart disease is recent and burgeoning. This review, categorized by application, should provide the reader with a comprehensive, albeit not complete, overview of $3 \mathrm{Dp}$ in congenital heart disease during the last decade.
\end{abstract}

Keywords: Three-dimensional printing (3Dp); rapid prototyping; congenital heart defect; cardiac surgery; simulation

Submitted Sep 03, 2019. Accepted for publication Oct 10, 2019.

doi: $10.21037 /$ jtd.2019.10.38

View this article at: http://dx.doi.org/10.21037/jtd.2019.10.38

\section{Introduction}

Three-dimensional printing (3Dp), also known as rapid prototyping, is not an entirely new technology but has relatively recently gained a foothold in the medical field. This is likely due to the widespread availability of smaller and more affordable printing units as well as recent advances in imaging acquisition and post-processing software. $3 \mathrm{Dp}$ technology has been applied widely in the surgical specialties. Although congenital heart surgery is epidemiologically a rather small problem when compared to things like "orthopedics", a lot of 3Dp work related to congenital heart problems has been done given the complexity, uniqueness and 3D nature of congenital heart lesions.

Virtually all parties involved in the care of these patients may find benefit related to $3 \mathrm{Dp}$. Surgeons may use them to better understand, plan and even simulate operations; patients and families may understand their disease better with the aid of such prints; medical trainees at all levels and cardiac nurses may gain additional understanding with the aid of 3D-printed models.
This review will briefly summarize the $3 \mathrm{Dp}$ process, and discuss, by application, the use of $3 \mathrm{Dp}$ in congenital heart disease.

\section{Process overview}

Somewhat ironically, $3 \mathrm{Dp}$ remains dependent on sets of two-dimensional (2D) data for construction of the 'blueprint' used to make the final product. These 2D data sets are typically derived from cross sectional imaging in the form of computed tomography (CT) or magnetic resonance imaging (MRI) scans in routine clinical use (1). 3D ultrasound (US) can also be used to generate data sets for printing which holds particular promise for congenital heart surgery given it is the default, and often sole, imaging modality for many complex congenital heart defects $(2,3)$. US is also easy to acquire and has a favorable safety profile, particularly compared to CT.

Different modalities have different strengths. US is superior at imaging valve tissue while CT is a better way to acquire data related to muscular structures and the blood/ tissue interface. Gosnell et al. elegantly showed that data 
sets derived from different modalities can be hybridized to produce a print that capitalizes on these differing qualities (4).

Whichever data set is to be used for printing must then be analyzed by a process called segmentation. During segmentation, pixels on each of the 2D data sets are either selected or de-selected. Usually, when the heart is the print subject, pixels representing cardiac structures are selected while pixels representing the blood pool are de-selected to produce a print displaying the hollow nature of the heart. These segmented data sets are then amalgamated and tessellated to produce a $2 \mathrm{D}$ representation of a $3 \mathrm{D}$ structure known as a stereolithographic or stl file which is the data input for 3Dp. The printer will serially "lay down" material to recreate the $3 \mathrm{D}$ structure. Depending on the print medium used there is often "scaffolding" material that can be removed after printing is complete and/or the medium is "cured" (5).

\section{Verification}

An important initial question regarding $3 \mathrm{Dp}$ is the precision with which the printed product recreates the structure being measured. While it is easy to compare the actual dimensions of the print to the digital source images, this really only verifies that the printing process is accurate related to the stereolithography input data (6). Some investigators have been able to correlate with anatomic measurements which is a better verification of the entire process (accurate image acquisition $\rightarrow$ accurate image analysis $\rightarrow$ accurate segmentation $\rightarrow$ accurate printing) (7). We co-authored a study involved verifying the accuracy of the $3 \mathrm{Dp}$ process using preserved cardiac autopsy specimens which allowed very precise measurements by multiple observers and utilizing multiple modalities (8). The $3 \mathrm{Dps}$ were found to be $90 \%+$ accurate relative to the cadaveric specimens.

\section{Applications}

\section{Surgical planning}

Even the normal heart is a complicated 3D structure. Congenital heart defects present a virtually unlimited combination of alterations related to internal and external elements, often yielding very complex and unique structures. On top of this, congenital heart defects are relatively rare. Therefore, individual surgeons are not able to see or experience all forms of congenital heart disease during training or practice. $3 \mathrm{Dp}$ represents an incremental step towards "viewing reality" pre-operatively and may also allow a surgeon who has never encountered a specific defect to understand it very well (9).

Surgeons work and perform operations in the $3 \mathrm{D}$ world and there is no way to fully represent $3 \mathrm{D}$ structures in $2 \mathrm{D}$ images. $3 \mathrm{D}$-printed models have been shown to substantially impact pre-operative surgical decision making in cases of complex congenital heart disease $(10,11)$. Preoperative understanding of anatomy is also important as it informs surgical exposure and technical planning which may have impact on intra-operative time, while the heart is arrested and time is of the essence. All congenital surgeons think about, and try to visualize the operation as part of the pre-operative planning and preparation process, and having a patient specific $3 \mathrm{D}$ model negates the need to create an amalgamated 3D mental image from 2D studies. In one study, $96 \%$ of surgeons agreed or strongly agreed that $3 \mathrm{D}$-printed models enhanced their pre-operative understanding and improved surgical planning (10).

For these reasons, the most common application to date for $3 \mathrm{Dp}$ in congenital heart surgery has been for preoperative planning. Intuitively this technique may provide benefit in almost any pre-operative circumstance but the literature largely reflects use in some specific situations.

\section{Double outlet right ventricle (DORV)}

Most cases of DORV present a special challenge to the congenital surgeon: to imagine something that is not there. Namely, an unobstructed pathway connecting the left ventricle (LV) to the aorta. The usual variables taken into account are the location and size of the ventricular septal defect (VSD), the presence of potentially obstructive subaortic conus muscle, the relationship to atrioventricular inflow valves and the volume of the right ventricle and right ventricular outflow tract that may be occupied by such a pathway. Many authors have found value in $3 \mathrm{Dps}$ to minimize misunderstanding and enhance communication between imagers and surgeons, understand the relevant anatomy, and decide on the best surgical approach and repair type (12). Zhao et al. operated on 25 patients with DORV and studied pre-operative 3D-printed models in $1 / 3$ of cases. While it is not clear these patients were selected randomly, cardiopulmonary bypass and cross-clamp times were lower in the $3 \mathrm{Dp}$ group although these differences were not significant. They did show a significant difference in time to extubation and intensive care unit length of stay, possibly suggesting improved operative results (13). 


\section{Aortic arch malformations}

Malformations of the aorta and its branches are frequently encountered by congenital heart surgeons. In some cases, the clinical issue is the presence of a vascular ring with compression of the esophagus and/or trachea. $3 \mathrm{Dp}$ has been used to aid in the surgical planning of multiple forms of vascular ring including Right aortic arch with Kommerell's diverticulum, and circumflex aorta $(14,15)$.

More commonly arch malformations are seen in the form of hypoplasia and/or interruption which limit the delivery and distribution of an adequate systemic cardiac output. Kiraly et al. made use of 3Dp to understand recurrent arch obstruction following an initial repair as well as plan a successful re-repair strategy (16). 3Dp has also been used to plan for repair of interrupted aortic arch (7).

\section{Tetralogy of Fallot with/without Major} ArterioPulmonary Collateral Arteries (TOF/MAPCAs) TOF is the most common form of cyanotic congenital heart disease and the results of surgical repair are a common benchmark upon which congenital surgeons are judged. Olejník et al. have utilized 3Dp to better understand the anatomy and prepare for operations on patients with TOF with and without MAPCAs (7). Anwar et al. have also used 3Dp to prepare for unifocalization in a patient with TOF/ MAPCAs (15).

\section{Mechanical circulatory support/transplantation}

Unfortunately, some patients with palliated congenital heart disease go on to require therapies for advanced heart failure in the form of mechanical circulatory support and transplantation. In virtually all cases of support with a ventricular assist device (VAD), application to a patient with congenital heart disease requires placement in a way that the device was not designed for. Farooqi et al. illustrated the utility of 3Dp to guide placement of VAD inflow cannulae in systemic right ventricles for patients with transposition of the great arteries palliated with atrial switch operations and for informing VAD placement in patients with Fontan circulation (17). Smith et al. and Bramlet et al. both have described 3Dp to aid with planning of transplant procedures for patients with situs inversus and dextrocardia and situs inversus with tricuspid atresia s/p Fontan palliation, respectively $(18,19)$.

\section{Other}

Sahayaraj et al. used information gained from a $3 \mathrm{Dp}$ to construct a tri-partite conduit from the $\mathrm{LV}$ to the pulmonary artery in a case of congenital corrected transposition of the great arteries with pulmonary atresia and pulmonary artery stenosis following modified BlalockTaussig shunt placement as a neonate (20). The ability to accurately predict the length of conduit, by pre-operative measurement, enabled planned construction of a conduit consisting of dacron, bovine jugular valve and homograft, taking advantages of the properties of each material.

We have utilized 3Dp in a complex case characterized by situs inversus with D-looped ventricles and D-transposition, a large inlet VSD, a regurgitant cleft mitral valve and pulmonary atresia that had been palliated with a Glenn shunt in Asia before being adopted by a family in the United States. While this combination of defects is exceedingly rare the understanding gained from the $3 \mathrm{D}$-printed model enabled understanding, planning and successful execution of the operation which required a Rastelli, hemi-mustard baffle, and mitral valve repair.

\section{Limitations}

There remains the issue related to "inflation" that is; surgery is done on an arrested heart devoid of blood. It is deflated. All preoperative imaging is done with the heart beating while "inflated" with blood. Only advances in printing materials that can mimic the qualities of cardiac tissue will be able to overcome this limitation. However, for most surgeons, this "inflation gap" is a smaller one to bridge than constructing a complete mental anatomic image from echocardiography, cross-sectional imaging and angiography. Additionally, 3Dps are static objects that can represent anatomy but do not provide information about physiology.

\section{Procedural simulation}

While having access to a $3 \mathrm{Dp}$ may help inform the choice of operation and enhance understanding of the anatomy, using the print to simulate or rehearse the operation takes it to another level of utility. This approach includes the benefits imparted with regards to planning but extends the role of the $3 \mathrm{Dp}$ into an increasingly practical realm. Using 3Dps for operative rehearsal of crucial steps of an operation has been adopted by multiple investigators and is becoming a more frequent application, as materials improve to allow increasingly realistic mimicking of tissue and conditions encountered in the operating room. The utility of this application of $3 \mathrm{Dp}$ remains ill-defined. However, a collaborative trial involving 17 centers in the United States, called 3D Heart, is currently enrolling patients and aims to 

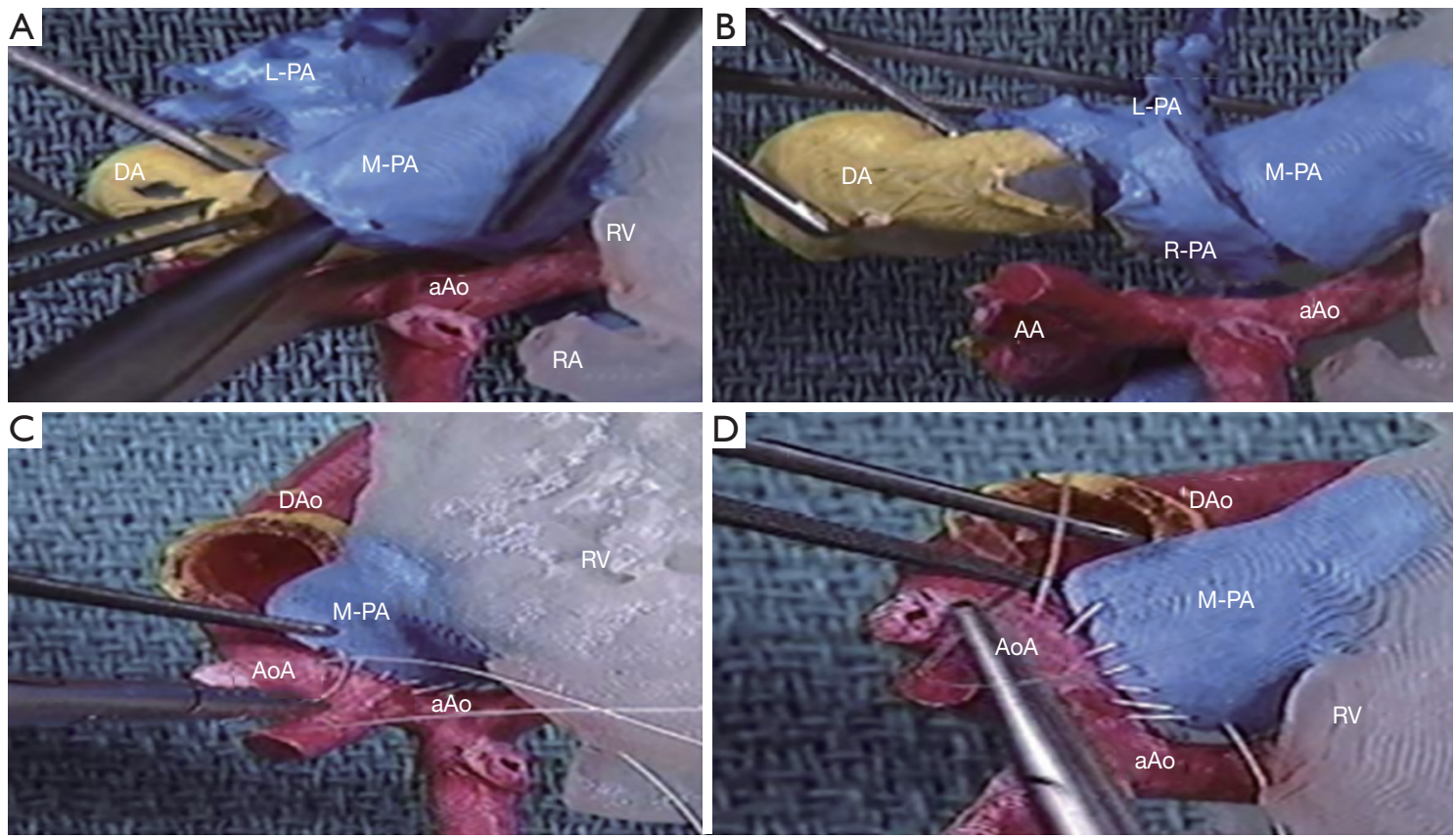

Figure 1 Image showing 3D-printed model being used for operative simulation of Norwood procedure. 3D, three dimensional. L-PA, left pulmonary artery; M-PA, main pulmonary artery; aAo, ascending aorta; DA, ductus arteriosus; RV, right ventricle; RA, right atrium; DAo, descending aorta; AoA, aortic arch.

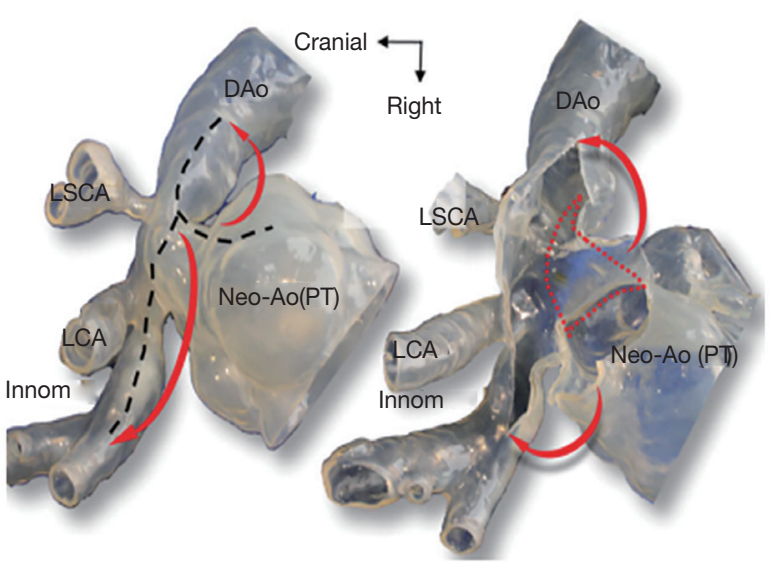

Figure 2 Image shows 3D-printed model being used to devise autologous repair of stenotic neo-aortic arch. 3D, three dimensional; DAo, descending aorta; LSCA, left subclavian artery; LCA, left common carotid artery; Neo-Ao, neoaorta; PT, pulmonary trunk; Innom, innominate artery.

quantitate the utility of $3 \mathrm{Dp}(21)$.

\section{Hypoplastic left heart syndrome (HLHS)}

It is a bit ironic that the first published report utilizing a
3D-printed model for surgical simulation in congenital heart surgery was for HLHS, one of the most complex and challenging lesions (22). Shiraishi et al. printed 3D models in both solid resin and flexible urethane mediums. The urethane models were noted to be a bit rubbery but the core elements of the Norwood procedure were able to be simulated (Figure 1). Kiraly et al. have also found 3Dp useful in preparing to operate on a 5-month-old child with arch obstruction following Norwood reconstruction. They also constructed solid resin and flexible models to understand the anatomy and simulate several repair options, settling on an autologous flap repair technique that they were able to devise and simulate using the model (16) (Figure 2).

\section{DORV}

DORV presents the congenital surgeon with a challenge of constructing an unobstructed intra-cardiac patch baffle. The ability to see the anatomy in three dimensions and simulate the operation has been an obvious application for $3 \mathrm{Dp}$ for multiple groups. Bhatla et al. reported an interesting case of DORV with a prominent conal septum in which $3 \mathrm{Dp}$ facilitated better understanding of the relevant anatomy and guided an atypical, right atrial approach for closure of the VSD (12). It was also clear that there was no possibility 
of an unobstructed LV-to-aorta pathway, and therefore the VSD was closed as a non-baffle patch and an arterial switch performed. Obviously, this was helpful for pre-operative decision making, operative readiness and discussion of risk with the family. Yoo et al. reported a summary of DORV cases utilizing $3 \mathrm{Dp}$ in which models were constructed of material that could be sutured upon and use to simulate the patch baffle operation (23) (Figure 3).

\section{Complete atrioventricular canal defect (CAVC)}

Repair of CAVC is difficult, in part due to the need to correctly partition the common atrioventricular valve into functional left and right valves. Scanlan et al. have shown the feasibility of printing accurate representations of

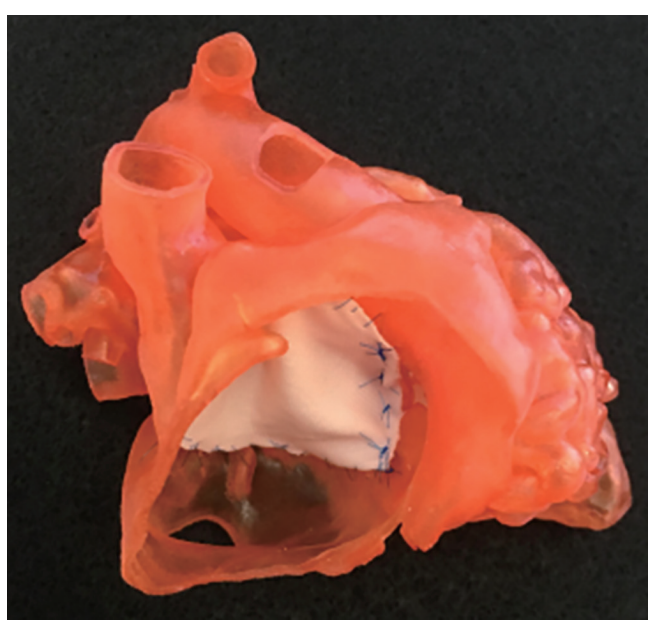

Figure 3 3D-printed model used to simulate intra-ventricular patch baffle repair of double outlet right ventricle. $3 \mathrm{D}$, three dimensional. atrioventricular valves through both a direct $3 \mathrm{Dp}$ and an indirect molding process (6) (Figure 4). Because the molding process utilized a silicone medium these valves were more pliable, held suture more reliably and were more suited for operative simulation. This is important work as it could be extrapolated to mitral valve repair in adults which can be difficult to teach in real time. A patient specific simulation platform may be invaluable for initial training of residents in basic mitral valve repair techniques.

\section{Left ventricular outflow tract obstruction (LVOTO)}

$3 \mathrm{Dp}$ has also been used to rehearse extended septal myectomy for patients with LVOTO related to hypertrophic cardiomyopathy (HCM). Rehearsed resection on a model allows the surgeon to perform resection and then inspect the model from multiple angles to determine where more or less resection can and/or should be safely performed. When printed as a 1:1 scale model, the volume of model resection performed can be quantified by liquid displacement and used as a "guide" in the operating room by measuring the volume displaced by operative specimens in a graduated cylinder on the back table (24). A similar approach using "virtual resection" of 3D CT scan reconstructions has been shown by Takayama to guide myectomy and approximate operative resection volumes (25).

We have also shown 3Dp of HCM hearts to be a useful tool in training residents to perform extended septal myectomy (26). Through a series of five simulated resections residents quickly moved from performing woefully inadequate resection to performing resections volumetrically on par with the attending surgeon (Figure 5).

We have also used $3 \mathrm{Dp}$ in preparation for our first

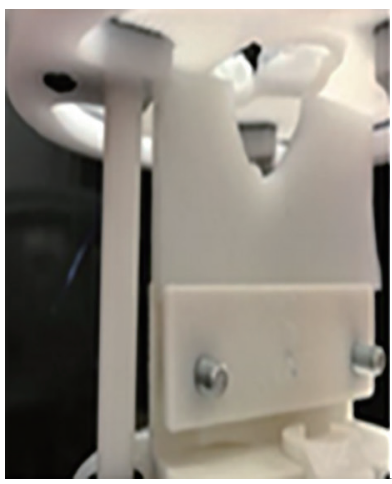

View "from below" of VSD piror to repair

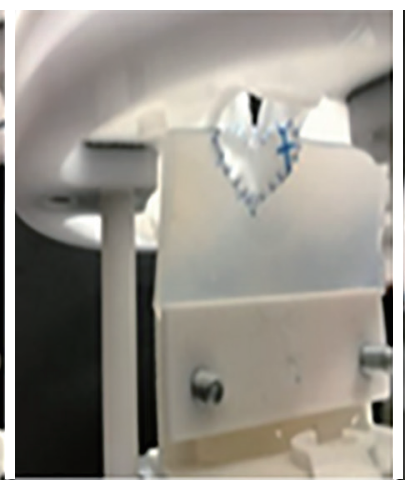

View "from below" after VSD repair

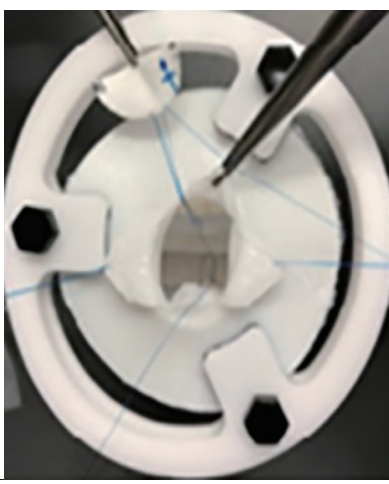

Simulated surgery with placement of VSD patch

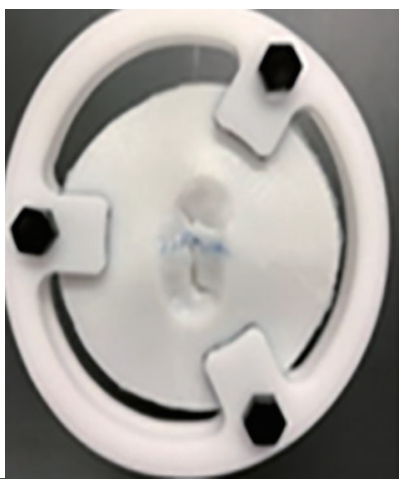

View "from above" after VSD closure and valve repair

Figure 4 Model used by Scanlan et al. to perform simulated repair of complete atrioventricular canal. VSD, ventricular septal defect. 

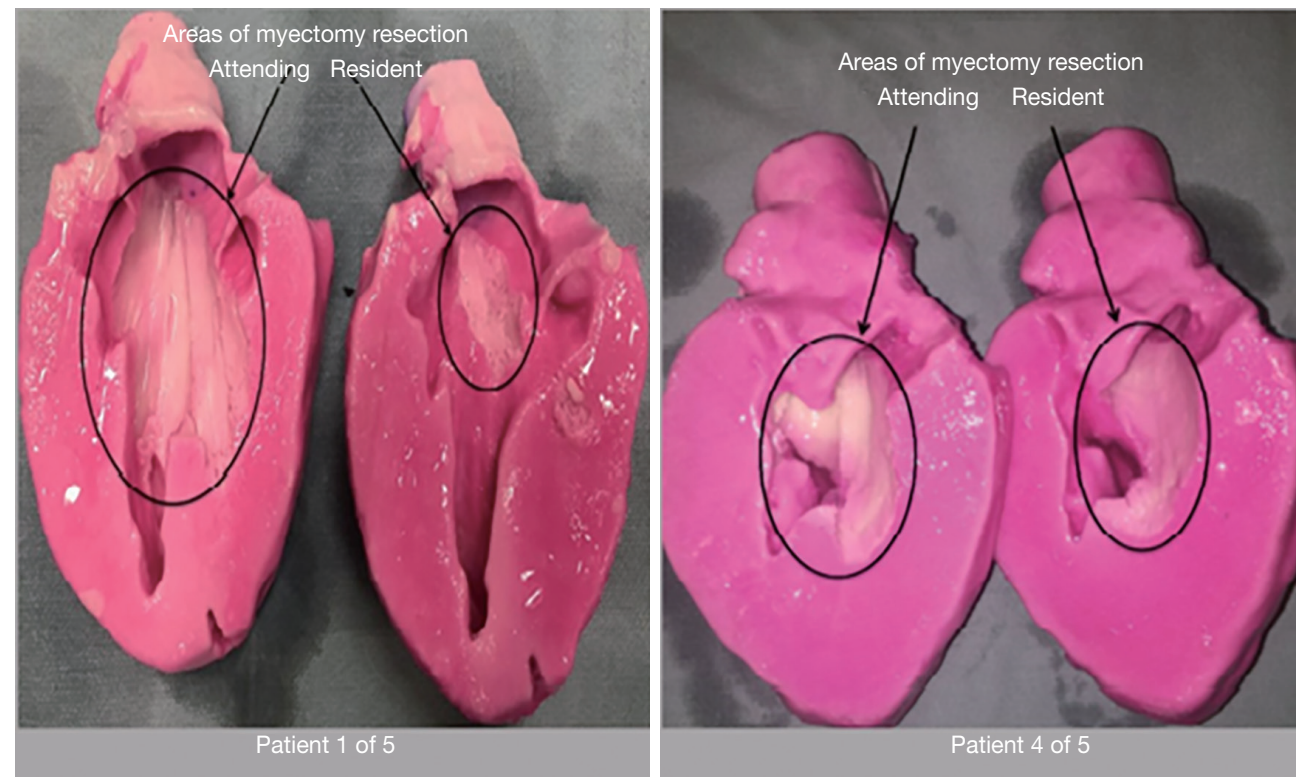

Figure 5 3D printed models used to rehearse patient specific extended septal myectomy in a resident training curriculum. In the first model on the left the residents performed a very minor resection compared to the attending surgeon. By the latter part of the experience resident resections were much more on par with attending resections.

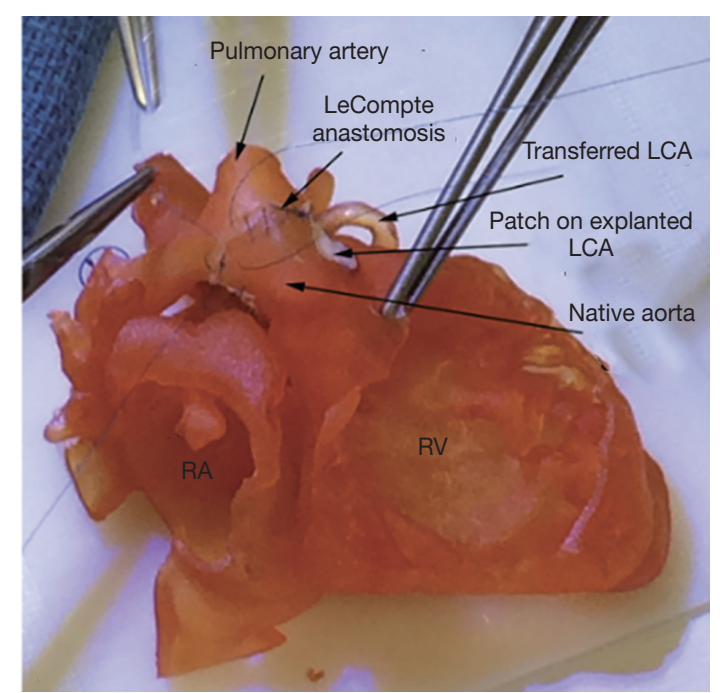

Figure 6 Model used in the Hands On Surgical Training (HOST) program by Yoo et al. to simulate the arterial switch operation. LCA, left common carotid artery; RV, right ventricle; RA, right atrium.

experience performing an extended myectomy via an apical approach (in combination with trans-aortic resection) in a patient with diffuse septal hypertrophy with excellent result.

HCM is a disease where the interplay of anatomy and physiology are tightly intertwined. The material science technology underlying 4D printing, in which model configuration can change in response to a stimulus (temperature, light, etc.) may expand the utility of such models and enable simulation of physiologic, as well as anatomic, conditions (27).

\section{D-transposition of the great arteries (D-TGA)}

The seminal experience to date regarding $3 \mathrm{Dp}$ and simulation of congenital heart operations was published by Yoo et al. (28) in 2017. Using 3Dps for what they termed "Hands On Surgical Training" (HOST) they reported on the experience of 81 surgeons at three different sites that performed simulated repairs of D-TGA, HLHS, DORV and TOF (Figure 6). In a survey of the HOST experience completed by 50 surgeons, the majority felt that the print anatomy was of excellent or good quality for surgical simulation. While the material was rated as "different" or "very different" by a similar majority most still felt the material was acceptable for simulation of procedures.

\section{Congenitally corrected transposition of the great arteries (CC-TGA)}

Isao Shiraishi authored the first report of surgical simulation, using 3D-printed models referenced above in 

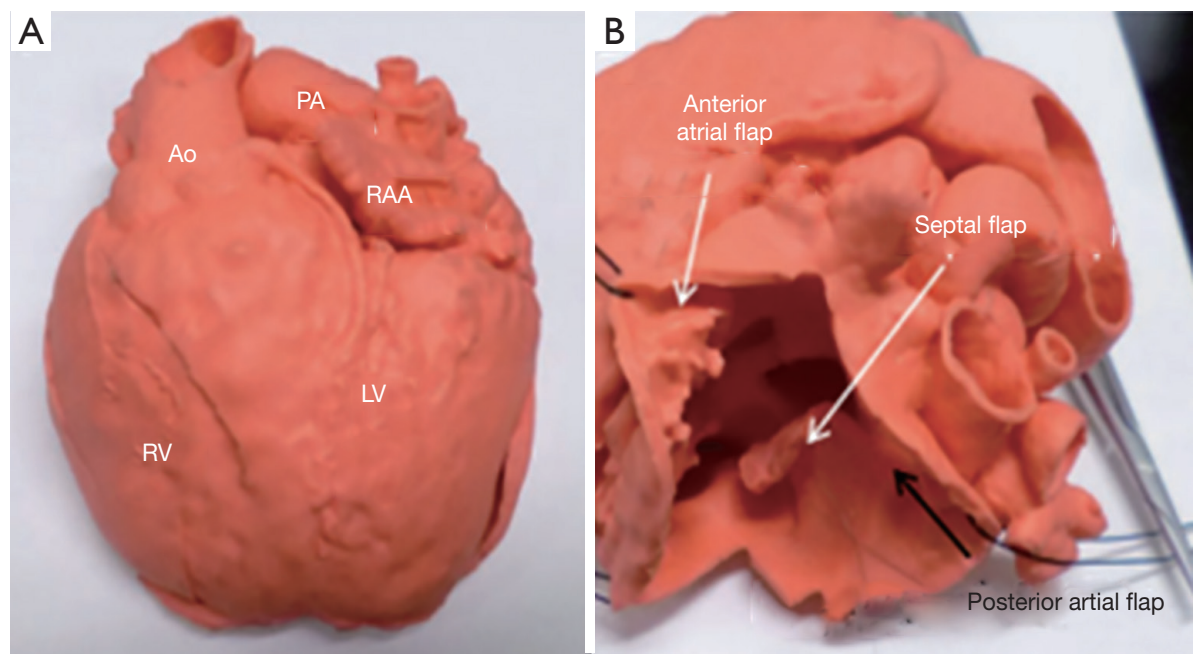

Figure 7 Model used to rehearse atrial switch component of a double switch operation. PA, pulmonary artery; Ao, aorta; RAA, right atrial appendage; RV, right ventricle; $\mathrm{LV}$, left ventricle.

the HLHS section, and has continued to innovate. The same group reported on their experience with 3D-printed models using a super-flexible material to rehearse operations for 20 patients with complex congenital heart disease (9). Five of the patients had CC-TGA and the models were used to rehearse double switch operations (Figure 7). This application may be particularly important in an era where a decreasing percentage of surgeons have personal experience with atrial switch techniques.

\section{Sinus venosus atrial septal defect with partial anomalous pulmonary venous return}

This lesion has been thought to be immune from catheterbased intervention based upon the need to not only both close the atrial connection but also baffle the anomalous vein. However, Velasco Forte et al. have described the use of 3Dp to plan for, simulate and perform endovascular repair of this lesion in multiple patients with acceptable outcomes in short term follow-up (29).

\section{The real power of 3Dp in congenital heart surgery}

Based upon experiences we have had, and the suggestion of other authors, the real power of $3 \mathrm{Dp}$ in congenital heart surgery is its ability to level the playing field $(9,10)$. With the aid of patient-specific modeling that can be used to envision, plan and even rehearse an operation, the fact that a particular surgeon has not previously encountered a specific defect becomes somewhat neutralized. Prior to the advent of $3 \mathrm{Dp}$, the mental framework necessary to tackle a complex defect was expected to only be possessed by a senior surgeon with extensive experience. The combination of advanced 2D imaging and $3 \mathrm{Dp}$, coupled with ready access to knowledge in the information age, allows surgeons without vast experience to report excellent results repairing complex defects they might not previously have felt empowered to address.

\section{Education}

\section{Medical students}

Simple VSDs are simple to conceptualize and the physiology is easily explained with a $2 \mathrm{D}$ drawing on a chalkboard. However, understanding the surgical anatomy, embryological differences between lesions and how such differences may influence physiology and their implications for repair is more difficult. Additionally, there are unique learning styles and many learners fall into visual or kinematic categories that may be aided by study of a physical model. Authentic models based on actual (not stylized) anatomy was shown to be helpful in a randomized study conducted by Su et al. where medical students were randomized to receive instruction on VSD with or without the aid of $3 \mathrm{D}$-printed hearts displaying membranous, muscular and subarterial VSDs (30). Student learning style was not evaluated but can be assumed to be normally 
(A) Model is fun

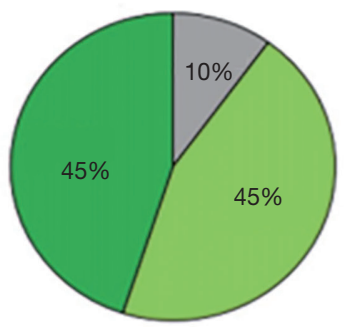

(C) Model improves visit

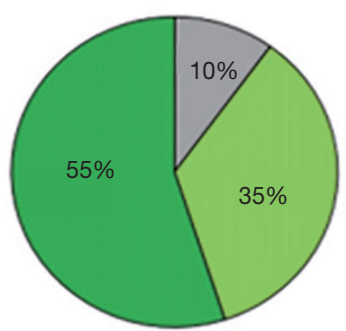

(B) Model helps understanding

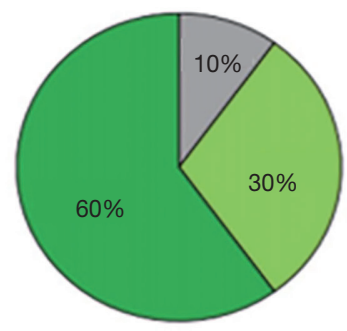

Strongly disagree

Disagree

Neutral

(D) Model made me anxious

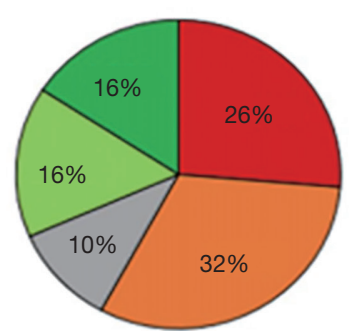

Agree

Strongly agree

Figure 8 Survey results from patients following surgical consultation with use of 3D-printed model of their heart. 3D, three dimensional.

distributed. In both subjective and objective assessments, the $3 \mathrm{Dp}$ group demonstrated superiority to the standard instruction group.

\section{Residents}

Pediatric residents are often tasked to aid in the care of children with congenital heart disease and it remains an important part of their training. However, as opposed to surgical residents who are afforded opportunities to correlate imaging studies with anatomy seen in the operating room, pediatrics residents are unlikely to have the benefit of hands-on anatomic experience. Costello et al. used 3D-printed models in a resident curriculum focused on the care of a children with VSD (31). Pre- and postcurriculum surveys demonstrated significant acquisition of knowledge related to VSD imaging by echo, VSD anatomy as experienced by surgeons in the operating room, and concepts in critical care of patients with VSD in the intensive care unit. In a similar study Loke et al. randomized pediatric residents to a standard TOF curriculum $v s$. one utilizing 3D-printed models. While knowledge acquisition was not significantly different, learner satisfaction was higher in the $3 \mathrm{Dp}$ group (32). Utilization of $3 \mathrm{Dp}$ in resident education may be one way to maintain interest in cardiology as a specialty and recruit pediatric cardiology fellows.

\section{Nurses}

Bedside nurses are the first line of detection and protection for hospitalized patients with congenital heart disease. Good nursing care requires knowledge of the underlying defects and associated physiology. A well-trained nurse will often be the first to detect signs of evolving physiology or that something is "not right". One hundred National Health System cardiac nurses in the United Kingdom were exposed to a curriculum using 3D-printed hearts displaying nine different pathologies (33). In curricular assessment 3 Dps were considered more informative than diagrams and a large majority ( $>70 \%)$ of nurses thought they helped in the appreciation of overall anatomy and spatial orientation.

\section{Patients}

It can be a daunting task to distill the essence of a congenital heart defect(s) during a relatively short office-based consultation with a patient and/or their family. Biglino et al. have explored the use of lesion specific 3D-printed models during consultative visits with adolescent patients and found that for $90 \%$ of patients, the models aided in understanding and improved the visit (34). Approximately a third of patients had some level of anxiety induced by "seeing their heart" but these opposing attitudes were not mutually exclusive (Figure 8). 


\section{Summary}

Like the imaging modalities that underpin it, $3 \mathrm{Dp}$ is an evolving technology. The use of $3 \mathrm{Dp}$ in congenital heart surgery seems to be especially valuable given the variety and complexity of anatomic variants seen in clinical practice. $3 \mathrm{Dp}$ may be applied in virtually any area of congenital heart disease ranging from consultation with a patient to education of a bedside nurse to operative rehearsal of complex intracardiac surgery.

\section{Acknowledgments}

Funding: None.

\section{Footnote}

Provenance and Peer Review: This article was commissioned by the Guest Editor (Raghav A. Murthy) for the series "Management of Congenital Heart Disease" published in Fournal of Thoracic Disease. The article was sent for external peer review organized by the Guest Editor and the editorial office.

Conflicts of Interest: The series "Management of Congenital Heart Disease" was commissioned by the editorial office without any funding or sponsorship. The authors have no other conflicts of interest to declare.

Ethical Statement: The authors are accountable for all aspects of the work in ensuring that questions related to the accuracy or integrity of any part of the work are appropriately investigated and resolved.

Open Access Statement: This is an Open Access article distributed in accordance with the Creative Commons Attribution-NonCommercial-NoDerivs 4.0 International License (CC BY-NC-ND 4.0), which permits the noncommercial replication and distribution of the article with the strict proviso that no changes or edits are made and the original work is properly cited (including links to both the formal publication through the relevant DOI and the license). See: https://creativecommons.org/licenses/by-nc-nd/4.0/.

\section{References}

1. Bortolotto C, Eshja E, Peroni C, et al. 3D Printing of CT Dataset: Validation of an Open Source and Consumer-
Available Workflow. J Digit Imaging 2016;29:14-21.

2. Samuel BP, Pinto C, Pietila T, et al. Ultrasound-Derived Three-Dimensional Printing in Congenital Heart Disease. J Digit Imaging 2015;28:459-61.

3. Chen SA, Ong CS, Hibino N, et al. 3D printing of fetal heart using 3D ultrasound imaging data. Ultrasound Obstet Gynecol 2018;52:808-9.

4. Gosnell J, Pietila T, Samuel BP, et al. Integration of Computed Tomography and Three-Dimensional Echocardiography for Hybrid Three-Dimensional Printing in Congenital Heart Disease. J Digit Imaging 2016;29:665-9.

5. Marro A, Bandukwala T, Mak W, et al. Three-Dimensional Printing and Medical Imaging: A Review of the Methods and Applications. Curr Probl Diagn Radiol 2016;45:2-9.

6. Scanlan AB, Nguyen AV, Ilina A, et al. Comparison of 3D Echocardiogram-Derived 3D Printed Valve Models to Molded Models for Simulated Repair of Pediatric Atrioventricular Valves. Pediatr Cardiol 2018;39:538-47.

7. Olejník P, Nosal M, Havran T, et al. Utilisation of three-dimensional printed heart models for operative planning of complex congenital heart defects. Kardiol Pol 2017;75:495-501.

8. Odeh M, Levin D, Inziello J, et al. Methods for verification of $3 \mathrm{D}$ printed anatomic model accuracy using cardiac models as an example. 3D Print Med 2019;5:6.

9. Hoashi T, Ichikawa H, Nakata T, et al. Utility of a super-flexible three-dimensional printed heart model in congenital heart surgery. Interact Cardiovasc Thorac Surg 2018;27:749-55.

10. Valverde I, Gomez-Ciriza G, Hussain T, et al. Threedimensional printed models for surgical planning of complex congenital heart defects: An international multicentre study. Eur J Cardiothorac Surg 2017;52:1139-48.

11. Bhatla P, Tretter JT, Ludomirsky A, et al. Utility and scope of rapid prototyping in patients with complex muscular ventricular septal defects or double-outlet right ventricle: Does it alter management decisions? Pediatr Cardiol 2017;38:103-14.

12. Bhatla P, Tretter JT, Chikkabyrappa S, et al. Surgical planning for a complex double-outlet right ventricle using 3D printing. Echocardiography 2017;34:802-4.

13. Zhao L, Zhou S, Fan T, et al. Three-dimensional printing enhances preparation for repair of double outlet right ventricular surgery. J Card Surg 2018;33:24-7.

14. Chen N, Zhu K, Zhang H, et al. Three-dimensional printing guided precise surgery for right-sided aortic arch 
associated with kommerell's diverticulum. J Thorac Dis 2017;9:1639-43.

15. Anwar S, Singh GK, Varughese J, et al. 3D printing in complex congenital heart disease: Across a spectrum of age, pathology, and imaging techniques. JACC Cardiovasc Imaging 2017;10:953-6.

16. Kiraly L, Tofeig M, Jha NK, et al. Three-dimensional printed prototypes refine the anatomy of post-modified norwood-1 complex aortic arch obstruction and allow presurgical simulation of the repair. Interact Cardiovasc Thorac Surg 2016;22:238-40.

17. Farooqi KM, Saeed O, Zaidi A, et al. 3D printing to guide ventricular assist device placement in adults with congenital heart disease and heart failure. JACC Heart Fail 2016;4:301-11.

18. Smith ML, McGuinness J, O'Reilly MK et al. The role of $3 \mathrm{D}$ printing in preoperative planning for heart transplantation in complex congenital heart disease. Ir J Med Sci 2017;186:753-6.

19. Bramlet M, Olivieri L, Farooqi K, et al. Impact of threedimensional printing on the study and treatment of congenital heart disease. Circ Res 2017;120:904-7.

20. Sahayaraj RA, Ramanan S, Subramanyan R, et al. 3D printing to model surgical repair of complex congenitally corrected transposition of the great arteries. World J Pediatr Congenit Heart Surg 2019;10:373-5.

21. Available online: https://opheart.org/medicalpros/3 dheart/

22. Shiraishi I, Yamagishi M, Hamaoka K, et al. Simulative operation on congenital heart disease using rubberlike urethane stereolithographic biomodels based on 3D datasets of multislice computed tomography. Eur J Cardiothorac Surg 2010;37:302-6.

23. Yoo SJ, van Arsdell GS. 3D printing in surgical management of double outlet right ventricle. Front Pediatr 2018;5:289.

24. Hermsen JL, Burke TM, Seslar SP, et al. Scan, plan, print, practice, perform: Development and use of a patientspecific 3-dimensional printed model in adult cardiac surgery. J Thorac Cardiovasc Surg 2017;153:132-40.

Cite this article as: Hermsen JL, Roldan-Alzate A, Anagnostopoulos PV. Three-dimensional printing in congenital heart disease. J Thorac Dis 2020;12(3):1194-1203. doi: $10.21037 /$ jtd.2019.10.38
25. Takayama H, Yu SN, Sorabella R, et al. Virtual septal myectomy for preoperative planning in hypertrophic cardiomyopathy. J Thorac Cardiovasc Surg 2019;158:455-63.

26. Hermsen JL, Yang R, Burke TM, et al. Development of a 3-D printing-based cardiac surgical simulation curriculum to teach septal myectomy. J Thorac Cardiovasc Surg 2018;156:1139-1148.e3.

27. Tamay DG, Dursun Usal T, Alagoz AS et al. 3D and 4D printing of polymers for tissue engineering applications. Front Bioeng Biotechnol 2019;7:164

28. Yoo SJ, Spray T, Austin EH 3rd, et al. Hands-on surgical training of congenital heart surgery using 3-dimensional print models. J Thorac Cardiovasc Surg 2017;153:1530-40.

29. Velasco Forte MN, Byrne N, Valverde I, et al. Interventional correction of sinus venosus atrial septal defect and partial anomalous pulmonary venous drainage: Procedural planning using 3D printed models. JACC Cardiovasc Imaging 2018;11:275-8.

30. Su W, Xiao Y, He S, et al. Three-dimensional printing models in congenital heart disease education for medical students: A controlled comparative study. BMC Med Educ 2018;18:178.

31. Costello JP, Olivieri LJ, Su L, et al. Incorporating threedimensional printing into a simulation-based congenital heart disease and critical care training curriculum for resident physicians. Congenit Heart Dis 2015;10:185-90.

32. Loke YH, Harahsheh AS, Krieger A, et al. Usage of $3 \mathrm{D}$ models of tetralogy of fallot for medical education: Impact on learning congenital heart disease. BMC Med Educ 2017;17:54.

33. Biglino G, Capelli C, Koniordou D, et al. Use of 3D models of congenital heart disease as an education tool for cardiac nurses. Congenit Heart Dis 2017;12:113-8.

34. Biglino G, Koniordou D, Gasparini M, et al. Piloting the use of patient-specific cardiac models as a novel tool to facilitate communication during cinical consultations. Pediatr Cardiol 2017;38:813-8. 